\title{
Relationship Between p16 Expression and Prognosis in Patients with Oropharyngeal Cancer Undergoing Surgery
}

\author{
KOTA KIDA $^{1}$, TOMONORI TERADA ${ }^{1}$, NOBUHIRO UWA ${ }^{1}$, YOSHIHIKO OMORI ${ }^{1}$, TAKASHI FUJII ${ }^{2}$, \\ YASUHIKO TOMITA ${ }^{3}$, KENZO TSUZUKI $^{1}$, HIROKI NISHIKAWA $^{4}$ and MASAFUMI SAKAGAMI ${ }^{1}$ \\ ${ }^{1}$ Department of Otolaryngology-Head and Neck Surgery, Hyogo College of Medicine, Hyogo, Japan; \\ ${ }^{2}$ Department of Head and Neck Surgery, Osaka International Cancer Institute, Osaka, Japan; \\ ${ }^{3}$ Department of Pathology Diagnosis, International University of Health and Welfare, Tokyo, Japan; \\ ${ }^{4}$ Center for Clinical Research and Education, Hyogo College of Medicine, Hyogo, Japan
}

\begin{abstract}
Background/Aim: Prognostic impact of p16 expression in patients with oropharyngeal squamous cell carcinoma (OSCC) undergoing surgery is not fully examined. The aim of this study was to clarify these issues. Patients and Methods: Sixty-four OSCC subjects were analyzed. Immuno-histochemical staining of p16, a surrogate marker for human papillomavirus (HPV), was performed histopathologically. Data were retrospectively analyzed according to pl6 positivity and factors linked to prognosis were also analyzed. Results: No significant difference was observed in the prognosis between the p16positive group $(n=28)$ and the p16-negative group $(n=36)$. In patients undergoing post-operative radiation, the p16positive group $(n=18)$ had a significantly better prognosis than the p16-negative group $(n=6)$. On multivariate analysis, transoral surgery was a significant predictor of overall survival ( $p=0.0173)$. Conclusion: Prognostic impact of p16 can be emphasized in a subgroup of OSCC patients undergoing surgery. Surgery with sufficient surgical margin may be chosen as the first treatment for HPV-negative OSCC in some cases.
\end{abstract}

Among head and neck squamous cell carcinomas (HNSCCs), the incidence of oropharyngeal SCC (OSCC) is increasing compared with carcinomas of other origins, thereby attracting public attention $(1,2)$. Like other malignancies in

This article is freely accessible online.

Correspondence to: Kota Kida, MD, Department of OtolaryngologyHead and Neck Surgery, Hyogo College of Medicine, 1-1, Mukogawacho, Nishinomiya, Hyogo, 663-8501, Japan. Tel: +81 798456111, Fax: +81 798456608, e-mail: kotakida@hyo-med.ac.jp

Key Words: Oropharyngeal cancer, surgery, Human papillomavirus, p16, clinical outcome. the upper gastrointestinal tract, OSCC is attributed to the carcinogenic effects of tobacco and alcohol (3). Prediagnosis cigarette smoking can be a prognostic factor for overall survival (OS) in OSCC patients (4). Therapeutic options for early stage OSCC include both surgery and radiotherapy as single treatment modality, while those for advanced stage include surgery, chemoradiation and chemotherapy $(5,6)$.

On the other hand, in recent years, human papillomavirus (HPV) is known to be involved, in addition to drinking and smoking, in oropharyngeal carcinogenesis $(1,7-10)$. HPV is the most common sexually transmitted disease. However, the overwhelming majority of patients with HPV clear the infection. A small percentage of patients with HPV develop oncogenic HPV types, especially HPV-16, and consequently, SCCs can develop in such patients. HPV causes more than $5 \%$ of malignancies worldwide $(1,7-10)$. Over $70 \%$ of OSCCs are currently thought to be linked to oncogenic HPV infection. Immunohistochemistry for $\mathrm{p} 16$ protein is often used as a surrogate marker for oncogenic HPV in the oropharyngeal tissues $(11,12)$. The clinical profile of patients with HPV-related OSCC differs quite notably from that of non-HPV-related OSCC, and the clinical outcome for HPV-related OSCC is reported to be significantly better due to high sensitivity for radiation therapy $(2,7,8)$.

Numerous clinical studies have examined the role of transoral surgical resection (SR) for the treatment of oropharyngeal malignancies and have shown similar clinical outcomes and improved functional outcomes compared with chemoradiation therapies $(5,13)$. However, the relationship between p16 expression and prognosis in OSCC patients undergoing surgery has not been fully examined. Thus, there is urgent need for elucidating these issues. The aims of this study are therefore to clarify the relationship between $\mathrm{p} 16$ expression and prognosis in patients with OSCC undergoing surgery. 
Table I. Baseline characteristics in the p16-positive group and the p-16 negative group.

\begin{tabular}{|c|c|c|c|}
\hline & p16-positive $(\mathrm{n}=28)$ & p16-negative $(n=36)$ & $p$-Value \\
\hline Gender, male/female & $25 / 3$ & $26 / 10$ & 0.1227 \\
\hline Age (years) & $61(41-80)$ & $64(41-78)$ & 0.5539 \\
\hline \multicolumn{4}{|l|}{ TNM classification } \\
\hline $\mathrm{T} 1$ or $2 / \mathrm{T} 3$ or 4 & $14 / 14$ & $24 / 12$ & 0.2073 \\
\hline $\mathrm{N}(+) / \mathrm{N}(-)$ & $21 / 7$ & $11 / 25$ & 0.0009 \\
\hline \multicolumn{4}{|l|}{ Clinical stage } \\
\hline Stage 1 or $2 /$ stage 3 or 4 & 6 vs. 22 & 19 vs. 17 & 0.0193 \\
\hline Post-operative radiation, yes/no & $18 / 10$ & $6 / 30$ & 0.0002 \\
\hline Maximum tumor size $(\mathrm{cm})$ & $3.2(0.3-9.5)$ & $3.0(0.4-8.0)$ & 0.6427 \\
\hline \multicolumn{4}{|l|}{ Primary tumor location } \\
\hline $\begin{array}{l}\text { Anterior wall/lateral wall/posterior wall/superior wall } \\
\text { Surgical procedure }\end{array}$ & $9 / 14 / 1 / 4$ & $13 / 16 / 2 / 5$ & 0.9582 \\
\hline Transoral surgery/Open surgery with external incision & $5 / 23$ & $12 / 24$ & 0.2541 \\
\hline (Reconstruction, yes/no) & $22 / 1$ & $20 / 4$ & \\
\hline
\end{tabular}

Data are presented as number or median value (range).

\section{Patients and Methods}

Between January 2000 and December 2009, 94 consecutive patients diagnosed as OSCC were admitted to the Department of Head and Neck Surgery, Osaka International Cancer Institute, Osaka, Japan (Former Osaka Medical Center for Cancer and Cardiovascular Diseases). All patients were treatment naive for OSCC. Of these, 64 patients for which immuno-histochemical staining for p16 in surgical specimens was available, were analyzed in this study. There were 51 male and 13 female patients with a median age of 62 years (range $=41-80$ years). For all cases, indication for surgery was carefully reviewed through discussion with surgeons, oncologist and radiologists.

Clinical stage for OSCC was determined based on Union for International Cancer Control (UICC) classification system (ver. 7) (14). In terms of $\mathrm{T}$ classification, $\mathrm{T} 1$ was found in 16 cases, $\mathrm{T} 2$ in 22 , $\mathrm{T} 3$ in 10 and T4a in 16. In terms of $\mathrm{N}$ classification, N0 was found in 32 cases, $\mathrm{N} 1$ in $6, \mathrm{~N} 2 \mathrm{a}$ in $1, \mathrm{~N} 2 \mathrm{~b}$ in $11, \mathrm{~N} 2 \mathrm{c}$ in 11 and $\mathrm{N} 3$ in 3.

In terms of patients with $\mathrm{p} 16$ positivity, a positive cell rate of $25 \%$ or more in tumor cells in the immuno-histochemical stain of p16 was defined as positive using surgical specimen, according to previous report (15). Positivity for p16 was determined by experienced pathologists.

Indications for post-operative radiation therapy were: (1) insufficient surgical margin of primary lesion; or (2) 2 or more lymph node metastases; or (3) the presence of lymph node metastases with extra-nodal invasion.

Baseline characteristics, details of uncontrollable lesions and clinical outcomes were retrospectively compared. Factors linked to OS and disease specific survival were analyzed using univariate and multivariate analyses.

The ethical committee in our hospital acknowledged our current study protocol (approval number, 1503315272) and this study strictly followed all regulations of the Declaration of Helsinki.

Statistical analysis. The categorical parameters in the p16-positive and p16-negative groups were analyzed by the Fisher's exact test, while the numerical parameters were analyzed either with unpaired
Student $t$-test or with Mann-Whitney $U$-test, as appropriate. OS and disease-specific survival curves were created by using the KaplanMeier method and compared by using the log-rank test. Variables with $p$-values $<0.05$ in univariate analysis were entered into the multivariate analysis with the Cox proportional hazards model. For the purpose of analyzing the significance of predictors in multivariate analyses, analyzed variables were divided by the median values for all cases and treated as nominal covariates. OS was defined as the time interval from SR until death (due to any cause) or the last follow-up visit. Disease specific survival was defined as the time interval from SR until death due to the disease (i.e., OSCC) or the last follow-up visit and all deaths with other causes were treated as censored population. Data were expressed as median values (range) unless otherwise stated. The significance threshold in the current analysis was set at $p<0.05$. All statistical analyses were performed using the JMP 13 software (SAS Institute Inc., Cary, NC).

\section{Results}

Baseline characteristics. Baseline characteristics in the p16-positive and p16-negative groups are demonstrated in Table I. There were 28 patients $(43.75 \%)$ in the p16positive group and 36 patients $(56.25 \%)$ in the p16-negative group. As for gender and age, no significant difference was found in the two groups $(p=0.1227$ for gender and $p=0.5539$ for age). As for $\mathrm{N}$ factor in TNM classification, the proportion of patients with positivity for $\mathrm{N}$ factor in the p16-positive group was significantly higher than that in the p16-negative group $(21 / 28 v s .11 / 36, p=0.0009)$. As for tumor location, both groups had the largest number of tumors located on the lateral side walls $(14 / 28(50.0 \%)$ in the p16-postive group and $16 / 36(44.4 \%)$ in the p16negative group). Post-operative radiation therapy was performed in 18 patients in the p16-positive group (total radiation dose: 50 gray (Gy) in one patient, 60 Gy in 15 , 

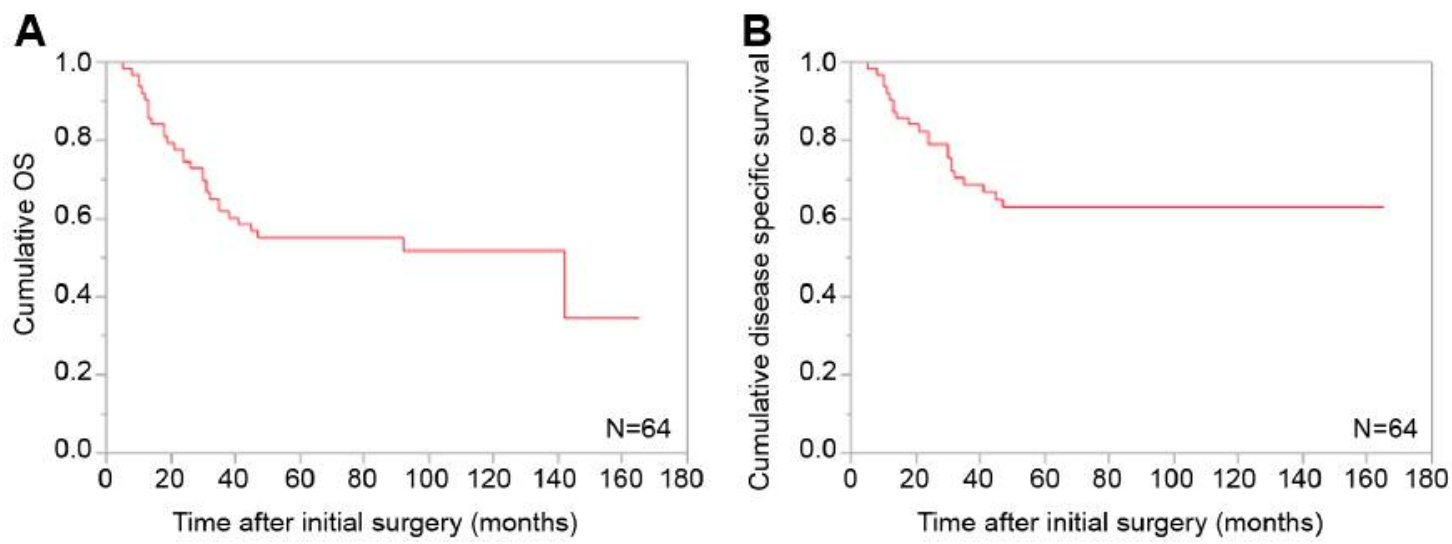

Figure 1. Cumulative overall survival (A) and disease-specific survival (B) for all cases ( $n=64)$.

A

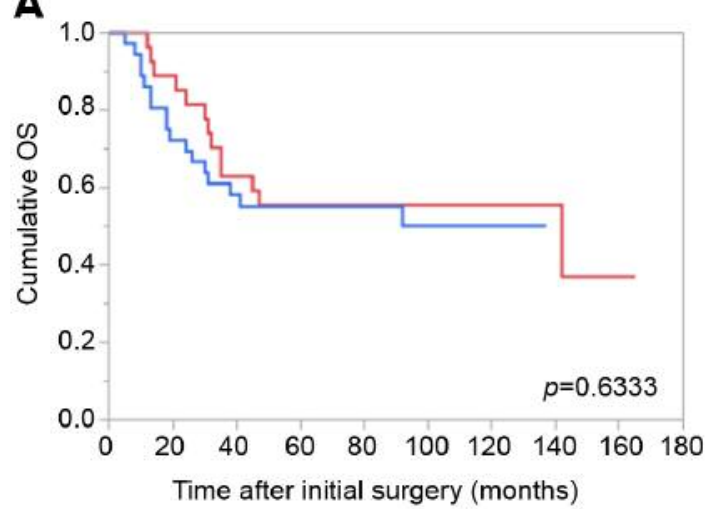

p16-positive group $(n=28)$
B

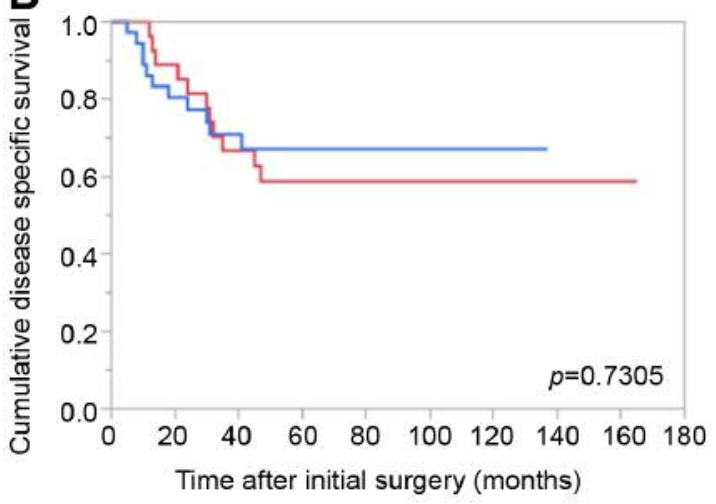

p16-negative group $(n=36)$

Figure 2. Cumulative overall survival (A) and disease-specific survival (B) for all cases stratified by p16 positivity.

$66 \mathrm{~Gy}$ in 2 and $70 \mathrm{~Gy}$ in none) and 6 patients in the p16negative group (total radiation dose: $50 \mathrm{~Gy}$ in one patient, $60 \mathrm{~Gy}$ in 4, $66 \mathrm{~Gy}$ in none and $70 \mathrm{~Gy}$ in one).

Cumulative OS rates for all cases and comparison of $O S$ and disease specific survival rates between the p16-positive group and the p16-negative group. The median follow-up period following SR for all cases was 55 months (range $=1$ 165 months). For all cases, the 1-, 3- and 5-year cumulative OS rates were $90.5,61.9$ and $55.3 \%$, respectively, while the 1-, 3- and 5-year cumulative disease specific survival rates were 90.5, 68.7 and 63.0\%, respectively (Figure 1A and B). The median follow-up period following SR was 55 months (range $=1-165$ months) in the p16-positive group and 50.5 months (range $=5-137$ months) in the p16-negative group. The 1-, 3- and 5-year cumulative OS rates were 96.3, 63.0 and $55.6 \%$, respectively, in the p16-positive group, and 86.1, 61.1 and $55.1 \%$, respectively, in the p16-negative group ( $p=0.633$; Figure 2A). The 1-, 3- and 5-year cumulative disease specific survival rates were $96.3,66.7$ and $58.8 \%$, respectively, in the p16-positive group, and 86.1, 70.9 and $67.2 \%$, respectively, in the p16-negative group $(p=0.7305$; Figure 2B).

Causes of mortality. During the observation period, 30 patients $(46.9 \%)$ succumbed to disease. In the p16-positive group, $13(46.4 \%)$ patients succumbed during the observation period. Causes for death were tumor progression in 11 and miscellaneous causes in 2. In the p16-negative group, 17 (47.2\%) patients succumbed during the observation period. Causes for death were tumor progression in 11 and miscellaneous causes in 6 . 
A

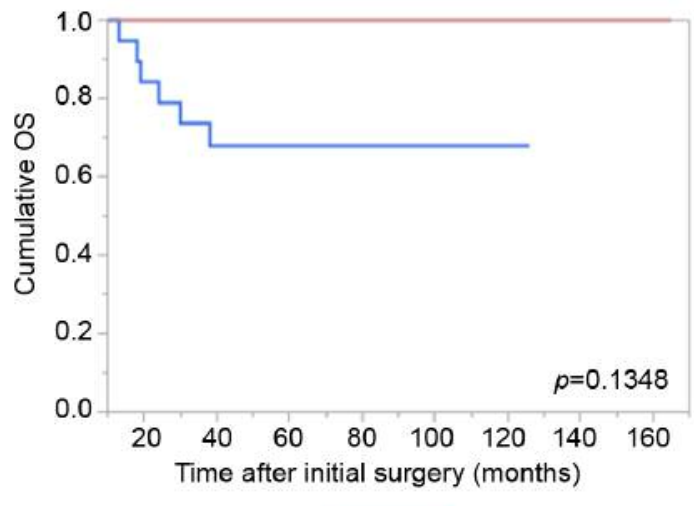

p16-positive group $(n=6)$
B

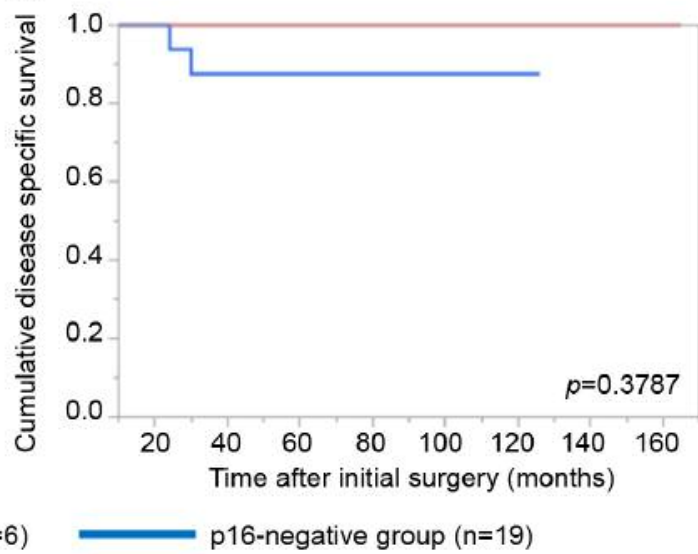

Figure 3. Cumulative overall survival (A) and disease-specific survival (B) in stage I or II patients $(n=25)$ stratified by p16 positivity.

\section{A}

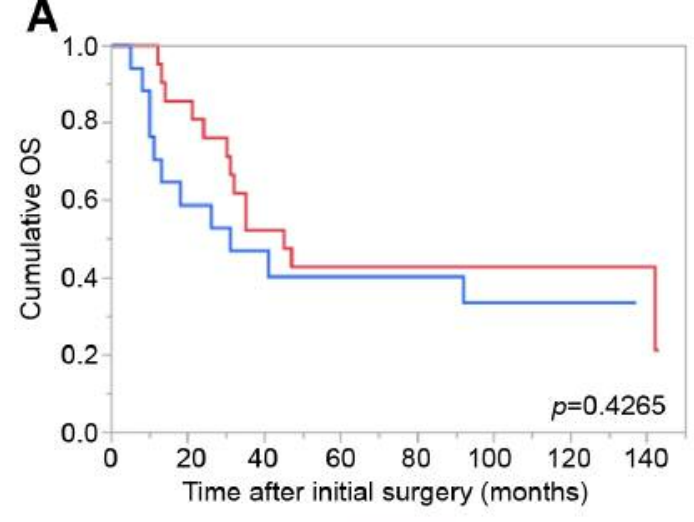

p16-positive group $(n=22)$

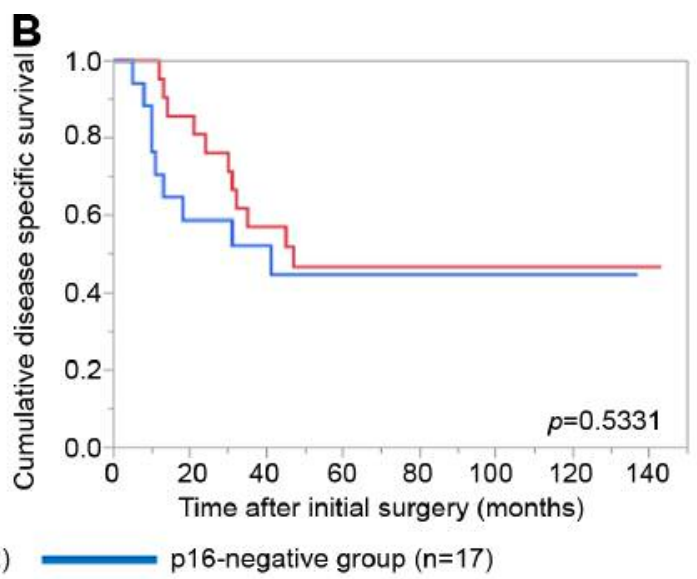

p16-negative group $(n=17)$

Figure 4. Cumulative overall survival (A) and disease-specific survival (B) in stage III or IV patients ( $n=39)$ stratified by p16 positivity.

Details of uncontrollable lesions as assessed by T, $N$ and $M$ factors in the p16-positive group and the p16-negative group during the follow-up period. Details of uncontrollable lesions in the p16-positive group and the p16-negative group were: $\mathrm{T}$ in 3 cases, $\mathrm{N}$ in $2, \mathrm{M}$ in $5, \mathrm{~T}$ and $\mathrm{M}$ in 1 and $\mathrm{N}$ and $\mathrm{M}$ in 1 in the p16-positive group and $\mathrm{T}$ in 3 cases, $\mathrm{N}$ in $3, \mathrm{M}$ in 4 and $\mathrm{N}$ and $\mathrm{M}$ in 1 in the p16-negative group ( $p=0.8664)$.

Comparison of OS and disease specific survival rates between the p16-positive group and the p16-negative group according to the tumor stage. In patients with stage I or II $(n=25)$, the 1-, 3- and 5-year cumulative OS rates were 100 , 100 and $100 \%$, respectively, in the p16-positive group $(n=6)$, and $100,73.7$ and $68.0 \%$, respectively, in the p16-negative group $(n=19)(p=0.1348 ;$ Figure 3A). The 1-, 3- and 5-year cumulative disease specific survival rates were 100, 100 and $100 \%$, respectively, in the p16-positive group, and 100, 87.5 and $87.5 \%$, respectively, in the p16-negative group $(p=0.3787$; Figure 3B).

In patients with stage III or IV, the 1-, 3- and 5-year cumulative OS rates were 95.2, 52.4 and 42.9\%, respectively, in the p16-positive group $(n=22)$, and 70.6, 47.1 and $40.3 \%$, respectively, in the $\mathrm{p} 16$-negative group $(\mathrm{n}=17)(p=0.4265$; Figure 4A). The 1-, 3- and 5-year cumulative disease specific survival rates were $95.2,57.1$ and $46.8 \%$, respectively, in the p16-positive group, and 70.6, 58.8 and $44.8 \%$, respectively, in the p16-negative group ( $p=0.5331$; Figure $4 \mathrm{~B})$.

Comparison of $O S$ and disease specific survival rates between the p16-positive group and the p16-negative group 

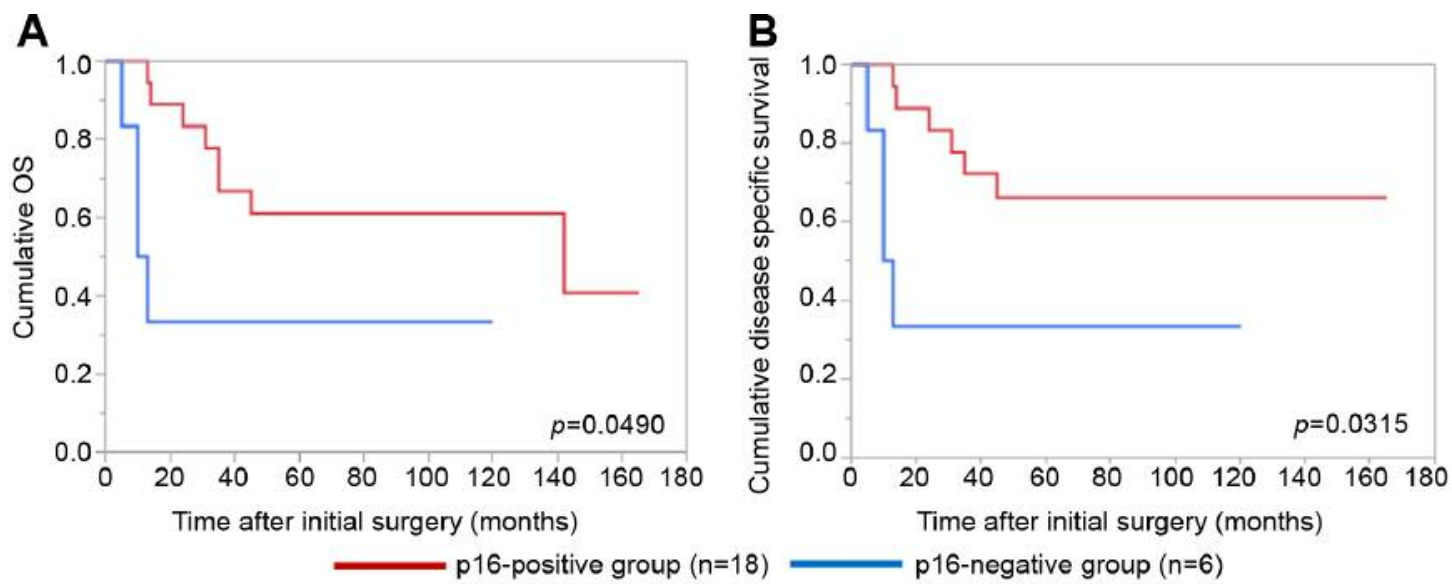

Figure 5. Cumulative overall survival (A) and disease-specific survival (B) in patients with postoperative radiation therapy ( $n=24)$ stratified by p16 positivity.
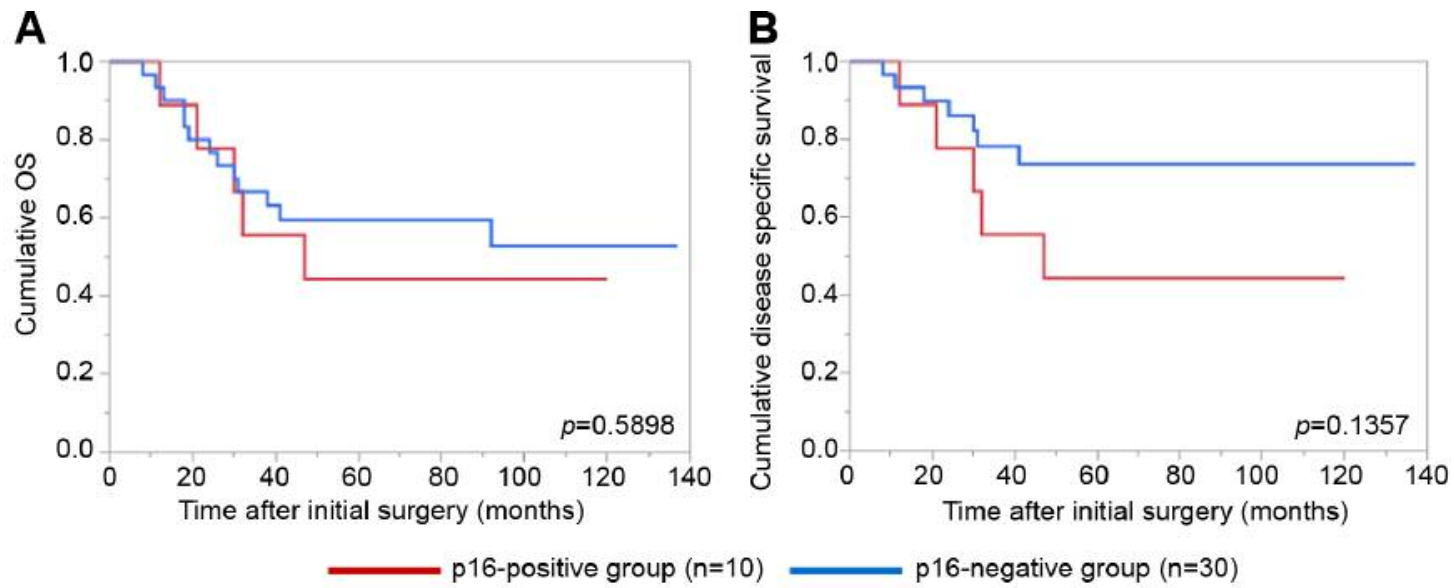

Figure 6. Cumulative overall survival (A) and disease-specific survival (B) in patients without postoperative radiation therapy ( $n=40)$ stratified by p16 positivity.

stratified by the post-operative radiation therapy. In patients that underwent post-operative radiation therapy $(n=24)$, the 1-, 3- and 5-year cumulative OS rates were 100, 66.7 and $61.1 \%$, respectively, in the p16-positive group $(n=18)$, and $50,33.3$ and $33.3 \%$, respectively, in the p16-negative group $(\mathrm{n}=6) \quad(p=0.0490 ;$ Figure 5A). The 1-, 3- and 5-year cumulative disease specific survival rates were 100, 72.2 and $66.2 \%$, respectively, in the p16-positive group, and 50.0, 33.3 and $33.3 \%$, respectively, in the p16-negative group $(p=0.0315$; Figure 5B).

Patients that did not have post-operative radiation therapy $(\mathrm{n}=40)$, the 1-, 3- and 5-year cumulative OS rates were 88.9, 55.6 and $44.4 \%$, respectively, in the p16-positive group $(\mathrm{n}=10)$, and $93.3,66.7$ and $59.4 \%$, respectively, in the $\mathrm{p} 16-$ negative group $(\mathrm{n}=30)(p=0.5898$; Figure 6A). The 1-, 3- and 5 -year cumulative disease-specific survival rates were 88.9 , 55.6 and $44.4 \%$, respectively, in the p16-positive group, and $93.3,78.3$ and $73.3 \%$, respectively, in the p16-negative group $(p=0.1357$; Figure 6B).

Comparison of $O S$ and disease-specific survival rates between stage III or IV patients with and without postoperative radiation therapy stratified by pl6 positivity. In stage III or IV patients with p16 positivity $(n=22)$, the $1-, 3$ and 5-year cumulative OS rates were 100, 62.5 and $56.3 \%$, respectively, in the postoperative radiation group $(n=16)$, and $80.0,40.0$ and $20.0 \%$, respectively, in the non-postoperative radiation group $(n=6)(p=0.0107$; Figure 7A) and the 1-, 3- 
A

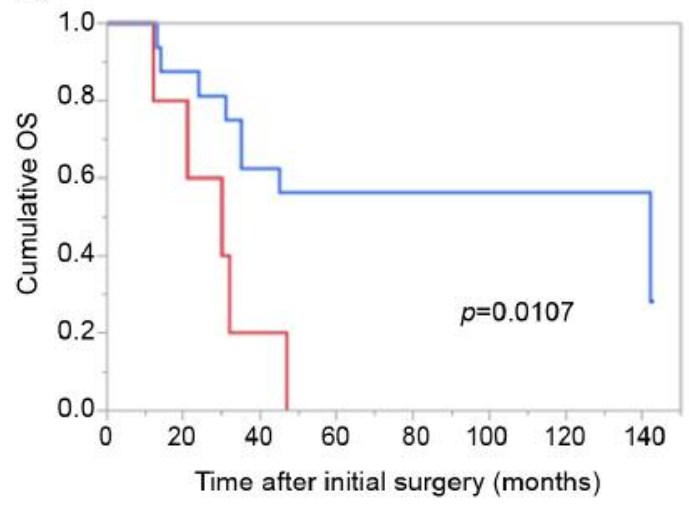

B

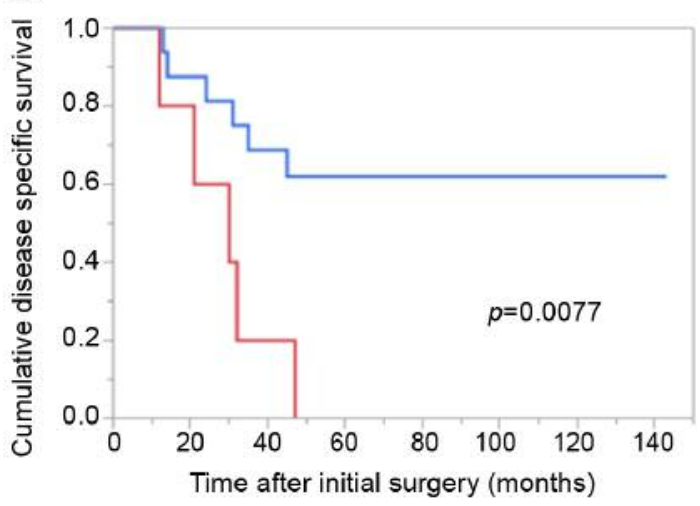

Radiation group $(n=16)$

Figure 7. Cumulative overall survival (A) and disease-specific survival (B) in the p16-positive stage III or IV patients with and without post-operative radiation therapy.

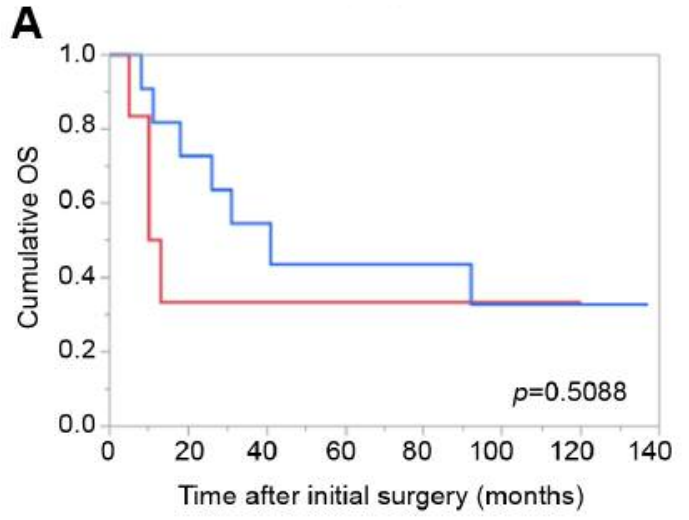

Radiation group $(n=6)$

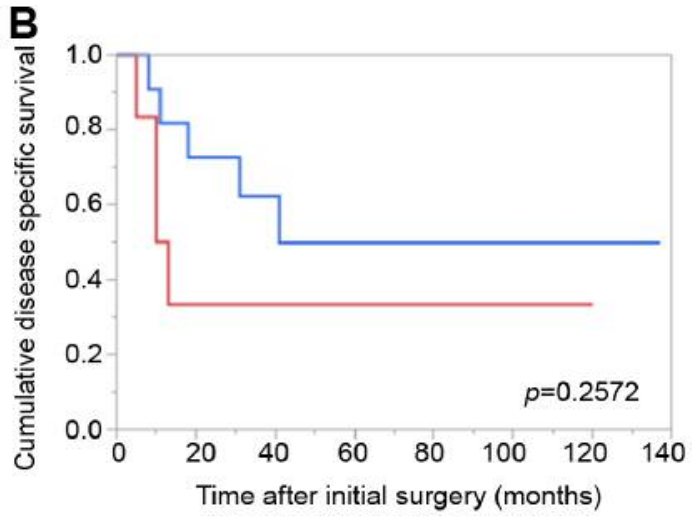

Non-radiation group $(n=11)$

Figure 8. Cumulative overall survival (A) and disease-specific survival (B) in the non-p16-positive stage III or IV patients with and without postoperative radiation therapy.

and 5-year disease-specific survival rates were 100, 68.8 and $61.9 \%$, respectively, in the postoperative radiation group, and $80.0,40.0$ and $20.0 \%$, respectively, in the non-postoperative radiation group ( $p=0.0077$; Figure $7 \mathrm{~B})$.

In stage III or IV patients without $\mathrm{p} 16$ positivity $(\mathrm{n}=17)$, the 1-, 3- and 5-year cumulative OS rates were 50.0, 33.3 and $33.3 \%$, respectively, in the postoperative radiation group $(n=6)$, and $81.8,54.6$ and $43.6 \%$, respectively, in the non-postoperative radiation group $(n=11) \quad(p=0.5088$; Figure 8A) and the 1-, 3- and 5-year disease specific survival rates were $50.0,33.3$ and $33.3 \%$, respectively, in the postoperative radiation group, and $81.8,62.3$ and $49.9 \%$, respectively, in the non-postoperative radiation group ( $p=0.2572$; Figure $8 \mathrm{~B})$.
Univariate and multivariate analyses of parameters contributing to overall survival and disease specific survival. The univariate analysis identified that the following factors significantly contributed to OS for all cases $(n=64)$ : T1 or 2 , yes/no $(p=0.0020)$; maximum tumor size $\geq 3 \mathrm{~cm}$, yes $/$ no $(p=0.0231)$; transoral surgery, yes/no $(p=0.0089)$ (Table II). The hazard ratios (HRs) and $95 \%$ confidence intervals (CIs) determined by multivariate analysis for the three significant variables (selected based on a $p<0.05$ in univariate analysis) are detailed in Table II. On multivariate analysis, $\mathrm{T}$ factor 1 or 2 was identified as marginally significant predictor associated with OS $(p=0.0809)$.

Likewise, the univariate analysis identified that the following factors significantly contributed to disease-specific 
Table II. Univariate and multivariate analyses of factors linked to overall survival and disease-specific survival.

\begin{tabular}{|c|c|c|c|}
\hline Overall survival & $\begin{array}{l}p \text {-Value } \\
\text { Univariate }\end{array}$ & $\begin{array}{l}\text { HR }(95 \% \mathrm{CI}) \\
\text { Multivariate }\end{array}$ & $\begin{array}{c}p \text {-Value } \\
\text { Multivariate }\end{array}$ \\
\hline Gender, male/female & 0.6492 & & \\
\hline Age $\geq 63$, yes/no & 0.6605 & & \\
\hline $\mathrm{T} 1$ or 2, yes/no & 0.0020 & $2.025(0.918-4.747)$ & 0.0809 \\
\hline $\mathrm{N}(+)$, yes/no & 0.0569 & & \\
\hline Post-operative radiation, yes/no & 0.9253 & & \\
\hline Max tumor $\geq 3 \mathrm{~cm}$, yes $/$ no & 0.0231 & $0.785(0.300-1.824)$ & 0.5949 \\
\hline Transoral surgery, yes/no & 0.0089 & $2.505(0.662-12.050)$ & 0.1990 \\
\hline \multirow[t]{2}{*}{ Disease specific survival } & $p$-Value & $\mathrm{HR}(95 \% \mathrm{CI})$ & $p$-Value \\
\hline & Univariate & Multivariate & Multivariate \\
\hline Gender, male/female & 0.4126 & & \\
\hline Age $\geq 63$, yes $/$ no & 0.9000 & & \\
\hline $\mathrm{T} 1$ or 2, yes $/$ no & 0.0003 & $2.176(0.900-5.796)$ & 0.0851 \\
\hline $\mathrm{N}(+)$, yes/no & 0.0119 & $0.828(0.293-2.045)$ & 0.6942 \\
\hline Post-operative radiation, yes/no & 0.4254 & & \\
\hline Max tumor $\geq 3 \mathrm{~cm}$, yes $/$ no & 0.0030 & $0.645(0.184-1.766)$ & 0.4163 \\
\hline Transoral surgery, yes/no & 0.0012 & $3.457 \mathrm{e}+9(1.699-1.982 \mathrm{e}+16)$ & 0.0173 \\
\hline
\end{tabular}

HR: Hazard ratio; CI: confidence interval.

survival for all cases: T1 or 2 , yes/no $(p=0.0003)$; $\mathrm{N}(+)$, yes/no $(p=0.0119)$; maximum tumor size $\geq 3 \mathrm{~cm}$, yes $/$ no $(p=0.0030)$; transoral surgery, yes/no $(p=0.0012)$ (Table II). The HRs and $95 \%$ CIs determined by multivariate analysis for the four significant variables are detailed in Table II. On multivariate analysis, transoral surgery was identified as a significant predictor associated with OS $(p=0.0173)$.

\section{Discussion}

The frequency of HPV-related HNSCCs is reported to be 35$80 \%$ in Western countries and $30-50 \%$ in Asian countries (9, 16-20). Since HPV-positive and negative HNSCCs present quite different clinical characteristics, personalized therapy according to HPV infection is currently being extensively studied.

Protein p16 is an important protein controlling the cell cycle, and its altered expression has been noticed in many types of cancers (21). In UICC/AJCC ver.8 published in 2017, OSCCs were classified into the p16-positive group and the p16-negative group $(11,12)$. Although p16 immunohistochemical staining cannot directly detect HPV, it was adopted as a surrogate marker to detect HPV infection indirectly because p16 overexpression is observed in many of HPV-related OSCCs. In terms of criteria regarding patients with p16-positivity, wide range of p16 immunopositive cut-off from $5-80 \%$ was reported in previous studies (15-19). Difference of clinical prognoses could not be recognized in these reports. Thus, in this study, experienced pathologists in our hospital defined patients with the immune-positive cell ratio of $25 \%$ or more in tumor cells as having p16 positivity, according to previous report (15). In this study, the p16-positive rate was $43.75 \%$, which is in line with previous data $(9,20,22-25)$.

In Western countries, regarding tumor stage of OSCCs, there are more reports in which the number of $\mathrm{T} 1$ or $\mathrm{T} 2$ is larger in the HPV-positive group than in the negative group, while regarding $\mathrm{N}$ factor, it is reported that the prevalence of patients with advanced $\mathrm{N}$ factor is higher in the HPV positive group than in the negative group, even in patients with less advanced $\mathrm{T}$ factor $(16,26,27)$. In our data, the proportion of $\mathrm{N}$ factor-positive patients was significantly higher in the $\mathrm{p} 16-$ positive group than in the p16-negative group. The higher proportion of $\mathrm{N}$ factor-positive patients in the p16-positive group can explain the higher proportion of stage III or IV patients in the p16-positive group in this study.

Previous reports have shown that HPV-positive OSCCs have favorable sensitivity to chemotherapy and radiotherapy and good prognosis $(7,8)$. However, in surgically treated OSCC cases, there are only few large studies regarding the prognostic impact of p16 expression. Quon, et al. reported that p16 was not a prognostic factor in resectable OSCC $(n=48)$ when treated with an initial transoral robotic surgery approach, which was similar to our current results (28). While in our subgroup analyses of patients with postoperative radiation therapy, patients in the p16-positive group had significantly better prognosis. Additionally, in the p16-postive stage III or IV patients, those that had 
postoperative radiation therapy had better prognosis than those without, however, in the non-p16-positive stage III or IV patients, those that had postoperative radiation therapy did not have better prognosis than those without. These results indicated that in the p16-positive group, OS rate can be expected to increase by postoperative radiation therapy, but not in the p16-negative group. Both in stage I or II and stage III or IV, p16-positive group had better prognosis in our results. These results may be linked to the effect of radiation therapy in the $\mathrm{p} 16$-positive group.

In a subgroup analysis of patients without post-operative radiation therapy, the p16-positive group did not survive longer than the p16-negative group. Rather, the p16-negative group had better prognosis than the p16-positive group. In a sense, for patients with non-HPV-related OSCC, the surgical strategy should be considered due to the poor response to radiation therapy. However, it is important to ensure sufficient surgical margin in such patients.

Previous studies reported that sensitivity to radiation therapy can differ according to tumor location or macroscopic tumor type $(29,30)$. In particular, OSCCs with invasion into the anterior pillar, soft palate and tongue base, and intrusive invasion type and ulcer formation type are reported to be associated with poor sensitivity to radiation therapy. In p16negative OSCCs with such poor response to radiation, surgical indication can be especially considered. However, extensive SR requires for reconstructive surgery, which can cause postoperative dysphagia and dysarthria. For surgical indications, careful consideration will be thus needed.

In our multivariate analysis of factors linked to OS or disease-specific survival, only transoral surgery was a significant factor. Transoral surgery is a minimally-invasive approach (31). Indication for transoral surgery is limited to small volume OSCCs and this can be associated with our current results.

\section{Conclusion}

Although our study was retrospective in its nature, our results demonstrated that the prognostic impact of p16 can be emphasized in OSCC patients undergoing post-operative radiation. In addition, in OSCC patients without HPV, indication for surgery should be strongly considered. Clinicians should be aware of these in daily clinical practice.

\section{Conflicts of Interest}

All Authors declare that they have no conflicts of interest.

\section{Acknowledgements}

The Authors gratefully acknowledge the radiologists at the Department of Radiation Oncology, Osaka International Cancer
Institute, for the radiotherapy, and the help they provided to our technical assistants, Mrs. Yui Okajima, Ms. Yumi Kida and Mrs. Midori Tanide.

\section{References}

1 Gillison ML, Koch WM, Capone RB, Spafford M, Westra WH, Wu L, Zahurak ML, Daniel RW, Viglione M, Symer DE, Shah KV and Sidransky D: Evidence for a causal association between human papillomavirus and a subset of head and neck cancers. J Natl Cancer Inst 92: 709-720, 2000.

2 Okami K: Clinical features and treatment strategy for HPV-related oropharyngeal cancer. Int J Clin Oncol 21: 827-835, 2016.

3 Granados-García M: Oropharyngeal cancer: an emergent disease? Salud Publica Mex 58: 285-290, 2016.

4 Giraldi L, Leoncini E, Pastorino R, Wünsch-Filho V, de Carvalho M, Lopez R, Cadoni G, Arzani D, Petrelli L, Matsuo K, Bosetti C, La Vecchia C, Garavello W, Polesel J, Serraino D, Simonato L, Canova C, Richiardi L, Boffetta P, Hashibe M, Lee YCA and Boccia S: Alcohol and cigarette consumption predict mortality in patients with head and neck cancer: a pooled analysis within the International Head and Neck Cancer Epidemiology (INHANCE) Consortium. Ann Oncol 28: 2843-2851, 2017.

5 Turner MT, Byrd JK and Ferris RL: Current Role of Surgery in the Management of Oropharyngeal Cancer. J Oncol Pract 12: 1176-1183, 2016.

6 Adelstein D, Gillison ML, Pfister DG, Spencer S, Adkins D, Brizel DM, Burtness B, Busse PM, Caudell JJ, Cmelak AJ, Colevas AD, Eisele DW, Fenton M, Foote RL, Gilbert J, Haddad RI, Hicks WL Jr, Hitchcock YJ, Jimeno A, Leizman D, Lydiatt WM, Maghami E, Mell LK, Mittal BB, Pinto HA, Ridge JA, Rocco J, Rodriguez CP, Shah JP, Weber RS, Witek M, Worden F, Yom SS, Zhen W, Burns JL and Darlow SD: NCCN Guidelines Insights: Head and Neck Cancers, Version 2.2017. J Natl Compr Canc Netw 15: 761-770, 2017.

7 Lassen P, Eriksen JG, Krogdahl A, Therkildsen MH, Ulhøi BP, Overgaard M, Specht L, Andersen E, Johansen J, Andersen LJ, Grau C and Overgaard J; Danish Head and Neck Cancer Group (DAHANCA): The influence of HPV-associated p16-expression on accelerated fractionated radiotherapy in head and neck cancer: Evaluation of the randomized DAHANC6 and 7 trial. Radiother Oncol 100: 49-55, 2011.

8 Fischer CA, Zlobec I, Green E, Probst S, Storck C, Lugli A, Tornillo L, Wolfensberger $\mathrm{M}$ and Terracciano LM: Is the improved prognosis of p16 positive oropharyngeal squamous cell carcinoma dependent of the treatment of the treatment modality? Int J Cancer 126: 1256-1262, 2010.

9 Marur S, D'Souza G, Westra WH and Forastiere AA: HPVassociated head and neck cancer: a virus-related cancer epidemic. Lancet Oncol 11: 781-789, 2010.

10 Berman TA and Schiller JT: Human papillomavirus in cervical cancer and oropharyngeal cancer: One cause, two diseases. Cancer 123: 2219-2229, 2017.

11 Mizumachi T, Homma A, Sakashita T, Kano S, Hatakeyama H and Fukuda S: Confirmation of the eighth edition of the AJCC/UICC TNM staging system for HPV-mediated oropharyngeal cancer in Japan. Int J Clin Oncol 22: 682-689, 2017.

12 Doescher J, Veit JA and Hoffmann TK: The 8th edition of the AJCC Cancer Staging Manual: Updates in otorhinolaryngology, head and neck surgery. HNO 65: 956-961, 2017. 
13 Monnier Y and Simon C: Surgery versus radiotherapy for early oropharyngeal tumors: a never-ending debate. Curr Treat Options Oncol 16: 42, 2015.

14 Edge SB and Compton CC: The American Joint Committee on Cancer: the 7th edition of the AJCC cancer staging manual and the future of TNM. Ann Surg Oncol 17: 1471-1474, 2010.

15 Klaes R, Friedrich T, Spitkovsky D, Ridder R, Rudy W, Petry U, Dallenbach-Hellweg G, Schmidt D and von Knebel Doeberitz M: Overexpression of p16 (INK4A) as a specific marker for dysplastic and neoplastic epithelial cells of the cervix uteri. Int J Cancer 92: 276-284, 2001.

16 Ang KK, Harris J, Wheeler R, Weber R, Rosenthal DI, NguyenTân PF, Westra WH, Chung CH, Jordan RC, Lu C, Kim H, Axelrod R, Silverman CC, Redmond KP and Gillison ML: Human papillomavirus and survival of patients with oropharyngeal cancer. N Engl J Med 363: 24-35, 2010.

17 Pai RK, Erickson J, Pourmand N and Kong CS: p16INK4A immunohistochemical staining may be helpful in distinguishing branchial cleft cysts from cystic squamous cell carcinomas originating in the oropharynx. Cancer Cytopathol 117: 108-111, 2009.

18 Yuen PW, Man M, Lam KY and Kwong YL: Clinicopathological significance of p16 gene expression in the surgical treatment of head and neck squamous cell carcinomas. J Clin Pathol 55: 5860, 2002.

19 Begum S, Gillison ML, Ansari-Lari MA, Shah K and Westra WH: Detection of human papillomavirus in cervical lymph nodes: a highly effective strategy for localizing site of tumor origin. Clin Cancer Res 9: 6469-6475, 2003.

20 Luginbuhl A, Sanders M and Spiro JD: Prevalence, morphology, and prognosis of human papillomavirus in tonsillar cancer. Ann Otol Rhinol Laryngol 118: 742-749, 2009.

21 Urszula C, Tomasz Z, Katarzyna N, Katarzyna RW, Jedrzej G, Aleksandra P, Mateusz O, Bartosz P, Marzenna PO and Piotr D: Expression of cell cycle-related proteins p16, p27 and Ki-67 proliferating marker in laryngeal squamous cell carcinomas and in laryngeal papillomas. Anticancer Research 37(5): 2407-2415, 2017.

22 Egawa N, Egawa K, Griffin H and Doorbar J: Human papillomaviruses; Epithelial tropisms, and the development of neoplasia. Viruses 7: 3863-3890, 2015.

23 Maruyama H, Yasui T, Ishikawa-Fujiwara T, Morii E, Yamamoto Y, Yoshii T, Takenaka Y, Nakahara S, Todo T, Hongyo T and Inohara H: Human papillomavirus and p53 mutations in head and neck squamous cell carcinoma among Japanese population. Cancer Sci 105: 409-417, 2014.
24 Zhang C, Deng Z, Chen Y, Suzuki M and Xie M: Is there a higher prevalence of human papillomavirus infection in Chinese laryngeal cancer patients? A systematic review and metaanalysis.Eur Arch Otorhinolaryngol 273: 295-303, 2016.

25 Hama T, Tokumaru Y, Fujii M, Yane K, Okami K, Kato K, Masuda M, Mineta H, Nakashima T, Sugasawa M, Sakihama N, Yoshizaki T, Hanazawa T, Kato H, Hirano S, Imanishi Y, Kuratomi Y, Otsuki N, Ota I, Sugimoto T and Suzuki S: Prevalence of human papillomavirus in oropharyngeal cancer: a multicenter study in Japan. Oncology 87: 173-182, 2014.

26 Posner MR, Lorch JH, Goloubeva O, Tan M, Schumaker LM, Sarlis NJ, Haddad RI and Cullen KJ: Human papillomavirus in oropharynx cancer in TAX 324-A subset analysis from an international phase III trial. Ann Oncol 22: 1071-1077, 2011.

27 Rischin D, Young RJ, Fisher R, Fox SB, Le QT, Peters LJ, Solomon B, Choi J, O'Sullivan B, Kenny LM and McArthur GA: Prognostic significance of p16ink-4a and human papillomavirus in patients with oropharyngeal cancer treated on TROG 02. 02Phase III trial. J Clin Oncol 28: 4142-4148, 2010.

28 Quon H, Cohen MA, Montone KT, Ziober AF, Wang LP, Weinstein GS and O'Malley BW: Transoral robotic surgery and adjuvant therapy for oropharyngeal carcinomas and the influence of p16 INK4a on treatment outcomes. Laryngoscope 123: 635$640,2013$.

29 Kraus DH. Vastola AP, Huvos AG and Spiro RH: Surgical management of squamous cell carcinoma of the base of the tongue. Am J Surg 166: 384-388, 1993.

30 Lee WR, Mendenhall WM, Parsons JT, Million RR, Cassisi NJ and Stringer SP: Carcinoma of the tonsillar resion: A multivariate analysis of 243 patients treated with radical radiotherapy. Head Neck 15: 283-288, 1993.

31 Howard J, Masterson L, Dwivedi RC, Riffat F, Benson R, Jefferies S, Jani P, Tysome JR and Nutting C: Minimally invasive surgery versus radiotherapy/chemoradiotherapy for small-volume primary oropharyngeal carcinoma. Cochrane Database Syst Rev 12: CD010963, 2016.
Received April 3, 2018

Revised May 9, 2018

Accepted May 10, 2018 